external irritation, but great additional benefit may be obtained by deadening the acuity of the sensory organs of sight and hearing. I well remember when $I$ was house physician at St. Bartholomew's Hospital having the charge of a case of hydrophobia in which strong tetanoid spasms had set in and these attacks were excited by the slightest noise or even by the sight of anyone moving in the room. In order to reduce these gources of irritation to a minimum I had the man's eyes blindfolded and his ears plugged with cotton-wool. Of course, it is needless to say that the patient did not recover; but I am sure of this, that by the measures adopted his last sufferings were greatly ameliorated, the convalsions being immediately lessened in frequency, duration, and in violence.

Worthing, June 20th, 1898. I am, Sirs, yours faithfully, W. T. WYATT.

\section{"PUBLIC SCHOOLS AND FOOD."}

\section{To the Editors of THE LANCET.}

SIRs,-With reference to the subject of school diet so ably and sensibly handled in THE LANCET of Jane 18th I would ask, Why should not the physiologist construct a model diet table for schools, just as has been done in the case of prisons and kindred institations with the very best results as regards the bealth of the inmates ? Such a model diet would at one and the same time be the healthiest and the cheapest. Without attempting to construct one myself I would throw out the following suggestions. Breakfast should consist chiefly of porridge and milk, brown bread should be substituted for white, and tea and alcohol should be banished. Care should be taken, moreover, to give food which requires a good deal of mastication. Our children are fed for the most part on soft and pappy foods which are swallowed after little or no mastication, with the result that the teeth and jaws are not properly exercised. This is, I am convinced, one of the chief canses of the decay of the teeth so common among us.

I am, Sirs, yours faithfally,

Wimpole-street, June 20th, 1898. HARRY CAMPBELL.

\section{"THE ALLEGED DEARTH OF QUALIFIED ASSISTANTS." \\ To the Editors of THE LANCET.}

SIRS,-In connexion with this subject, and more especially with a letter from "G. P." in the British. Medical Journal of June 11th, it would be very interesting to know what "G. P." does really consider a "tempting" salary to offer to a qualified assistant. I bave for the last few years been a constant peruser of the advertisement columns of THE LANCET and the British Medieal Journal and I fail to recall to $m y$ memory any offer of such an alluring character as hinted at by "G. P." appearing in them, or, moreover, being made through the medium of an agent. Take, for instance, last week's medical journals: there are some twelve indoor appointments and six outdoor ones of which the salary is stated, the average remuneration of the former working out at some $f 98$ per annum; of the latter - two with unfurnished houses, three with rooms and attendance, and one with unfurnished houseat the munificent sum of $£ 138$ per annum. Surely none of these offers can be a repetition of that "tempting" one that "G. P." almost pitifully tells us of ? I do not know how "G. P." arrives at the conclusion that there are so many vacancies for qualified assistants, but admitting that such is the case $I$ trust that most of these vacancies will remain unfilled until the monetary inducement for employment in this capacity is substantially increased and until the status, comfort, and general treatment of the qualified assistant are greatly improved. This piteous plaint of the scarcity of the qualified assistant is only a phase of the agitation for the retention of the unqualified one, but the sooner those men who have been employing the latter kind of aid make up their minds that the decision of the Council is irrevocable, the sooner will there be-owing to the better position and salary offered them-a sufficient supply of qualified men.

It is not, however, altogether the financial question which causes men to " bar" assistantships so persistently. Principals should bear in mind that they cannot treat men their equals in birth, if not of better, and in a great many instances professionally and generally better educated, as they have hitherto treated the broken-down failure or, in so many cases, the drunken wastrel sine diploma but with full curriculam. There is, again, another factor to be considered. The young practitioner has recognised the fact that the action of the Council has placed him in a much better position to combat the game of "grab" played by so many men who, finding that they have much more than they can do, are not willing to let the young ones have a chance, but "sweat" two, three, even five assistants, qualified and unqualified. Apropos of "sweating " there is an advertisement offering a man $£ 150$ per annum for working a branch avowedly worth $£ 700$ per annum. Surely this is "sweating" pure and simple, but he can now make his bid for a fair share of patronage, assured that-if the Council does its duty-he will be protected from the "underbidding" opposition of the unqualified and that the trading tactics of the "limited liability company" class of practitioner will be materially hampered. I challenge his statement that death and retirement absorb some 600 men annually. I have not the means of verification at hand, but he will find, I think, that during the last few years a surplus of some 300 or 400 (over and above the removals from the two causes mentioned) has been added yearly to the Register. As to his medical friend who was unable to obtain a "locum"-even for an advance of 25 per cent. on the usual terms-if he will consult the columns of the medical journals he will find (omitting the various agencies) some eight or nine gentlemen ready to accommodate him, though they require for remuneration something more than the benefits of "bracing air and an interesting country," so ingenuously offered by a practitioner as the sole salary for a three weeks" "locum"25 per cent. increase on the locum's "usual terms"! Ye gods ! I am in want of neither assistantship nor "locum" myself-as a matter of fact I am not in " general practice," else I might almost be tempted to offer my services to this belated and almost recklessly extravagant individual.

I am, Sirs, yours faithfully,

June 20th, $1898 . \quad$ M.A. Cantab., M.A., M.B. Dublin.

To the Editors of THE LANCET.

SIRs,-The continuance of the correspondence against the act of the General Medical Council re unqualified assistants has a tendency at first sight to make one think that it has not been a popular one. From a personal knowledge of several large Lancashire towns I do not believe such to be the case, the different medical societies having approved of it. Nor have I noticed as an effect any more activity on the part of midwives, as was suggested by a correspondent in THE LANCET of Jane 18th. It appears to me that it must be the unqualified men and those who have made ase of them that are keeping ap the agitation. Amongst the younger men in these towns there is much jabilation and in the case of those who are assistants it has not only improved their status but has considerably improved their salaries. In one of these towns I know personally four men who were until recently diagnosing, prescribing, \&c., daily who have never been near a medical school and who are ignorant of the radiments of anatomy and physiology. It is this class that medical men want to see abolished. One can almost excuse the maintenance of a man who has really tried the legitimate study of medicine and has not succeeded in finishing his task, but to see qualified men wanting to maintain those whose knowledge is equivalent to that of a quack is a puzzle to me. I am, Sirs, yours faithfully,

June 20th, 1898.

An Assistant, M.D.

Boric ACID IN BuTter.-At the quarterly meeting of the Local Government Committee of the Glamorganshire County Council held on Jane 16th the county analyst (Mr. C. A. Seyler) presented his quarterly report. This stated that of 38 samples of butter which had been examined 25 were free from boric acid, the remaining 13 contained the acid, but the amount used had now decreased below the limit imposed by the conncil and in no case exceeded 05 per cent. Mr. Seyler had examined 5 hams, all of which contained boric acid, the average giving 024 per cent., and he suggested that the same limit should be placed on ham as on butter-viz, 05 per cent. The committee adopted the report. 